\title{
Determination of Ciprofloxacin Hydrochloride by a Flow Injection Chemiluminescence inhibition method
}

\author{
Yang $\mathrm{Chi}^{1,}$, a Ren Nailin ${ }^{2, b *}$ \\ ${ }^{1}$ Chemistry department, Hanshan normal university, Chaozhou, China \\ ${ }^{2}$ Chemistry department, Hanshan normal university, Chaozhou, China \\ ayangc@hstc.edu.cn, bhsrnl@163.com
}

Key words: Chemiluminescence inhibition; Flow injection ; Ciprofloxacin Hydrochloride; Rhodamine B

Abstract: On the basis of Ce (IV) and rhodamine B obvious light signal under the acid medium, the $\mathrm{Ce}(\mathrm{IV})$-rhaodamine $\mathrm{B}-\mathrm{H}_{2} \mathrm{SO}_{4}$ hemiluminescence system was established. In this paper, the ciprofloxacin hydrodchloride under the concentration of less than $1.0 \times 10^{-5} \mathrm{~g} / \mathrm{mL}$ was explored, and a new determination of ciprofloxacin hydrochloride by using flow injection chemiluminescence inhibition was established. Under the best experimental conditions, the relationgship of the chemiluminescence reduced value $\Delta I$ with the concentration of ciproflocacin haydrochloride in $6.0 \times 10^{-7} \sim 8.0 \times 10^{-6} \mathrm{~g} / \mathrm{mL}$ was linear within a detection limit of $2.0 \times 10^{-7} \mathrm{~g} / \mathrm{mL}$. the relative standard deviation is $2.0 \%$ by 11 parallel determinations of ciprofloxacin hydrochloride which the concentration is $5.0 \times 10^{-6} \mathrm{~g} / \mathrm{mL}$.

\section{Introduction}

Ciprofloxacin Hydrochloride (CIP) is the third generation synthetic fluoroquinolones' drug. This kind of drugs exhibits high activity against a broad variety of bacteria with high antibacterial activity, low toxicity and completely orally absorption, which has been widely used in clinic medicine and in preventing and curing aquatic livestock bacteriosis. Capillary Electrophoresis ${ }^{[1,2]}$, High performance liquid chromatography (HPLC) ${ }^{[3,4]}$, Spectrophotometry ${ }^{[5]}$ and Flow-injection chemiluminescence ${ }^{[6]}$ have been used for determination of this kind of drugs. The Flow-injection chemiluminescence has the advantages of simple equipment, easy operation and high sensitivity. In this paper, the chemical luminescence behavior of Rhodamine B and Ciprofloxacin hydrochloride in sulfuric acid medium with cerium (IV) has been studied, and the new determination of ciprofloxacin hydrochloride by using Flow injection chemiluminescence was established.

\section{Experimental}

\section{Apparatus and Reagents}

\section{Apparatus}

Flow injection chemiluminescence analyzer (IFFM-E type, Xi'an Rui Mai electronic technology Co., LTD.).

\section{Reagents}

Rhodamine B (Tianjin Damao Chemical reagent factory); Ammonium ceric sulfate (Chinese medicine (group) company Shanghai chemical reagent);

Ciprofloxacin hydrochloride stock solution $(1.0 \mathrm{mg} / \mathrm{mL}): 50 \mathrm{mg}$ reference substance of Ciprofloxacin hydrochloride was Accurately weighed in $50 \mathrm{~mL}$ volumetric flask, and was diluted to the required concentration by distilled water;

Rhodamine B stock solution $(1.0 \mathrm{mmol} / \mathrm{L}): 0.0239 \mathrm{~g}$ reference substance of Rhodamine B was Accurately weighed in $50 \mathrm{~mL}$ volumetric flask, and was diluted to the required concentration by 0.10 $\mathrm{mol} / \mathrm{L} \mathrm{H}_{2} \mathrm{SO}_{4}$;

Ammonium ceric sulfate stock solution (20mmol/L): $1.0965 \mathrm{~g}\left(\mathrm{NH}_{4}\right)_{2} \mathrm{Ce}\left(\mathrm{NO}_{3}\right)_{2}$ was prepared to 100 $\mathrm{mL} 20.0 \mathrm{mmol} / \mathrm{L}$ Ammonium ceric sulfate stock solution by $20 \mathrm{~mL} 1.0 \mathrm{~mol} / \mathrm{L} \mathrm{H}_{2} \mathrm{SO}_{4}$, and was diluted to the required concentration by $0.10 \mathrm{~mol} / \mathrm{L} \mathrm{H}_{2} \mathrm{SO}_{4}$. 
The reagents above are analysis pure, The water that used in this study is distilled water.

\section{Procedure}

In the flow system, the sample solution was mixed with Rhodamine B solution in the tee. When the fluid was flowed steady, the mixture would be flowed through the injector and mixed with cerium(IV) solution to the flow cell, and made the chemiluminescence. The chemiluminescence intensity was detected, and quantified by relative Chemiluminescence, which shown schematically in Fig. 1. As the blank luminescence signal is $\mathrm{I}_{0}$ and the sample luminescence signal is $\mathrm{I}_{\mathrm{S}}$, the relative Chemiluminescence is $\Delta I\left(\Delta I_{0}=I_{S^{-}} I_{0}\right)$.

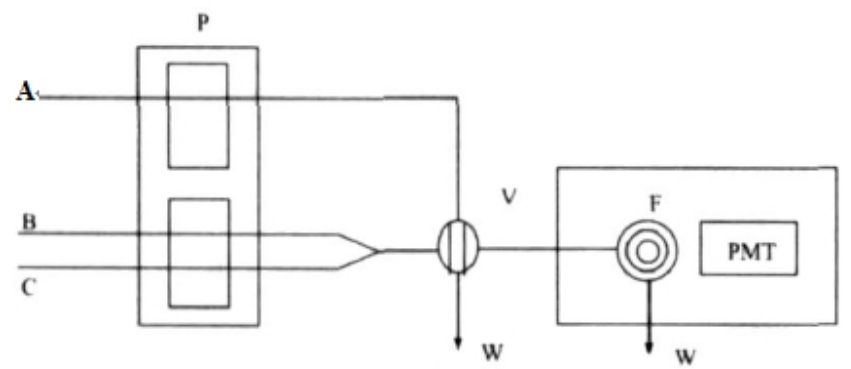

Fig 1 Schematic description of flow injection chemiluminescence system.

P: peristaltic pump; V: injector; F: flow cell; PMT: photomultiplier tube;

W: waste liquid; A:Ammonium ceric sulfate solution;

B:sample solution; C:Rhodamine B solution

\section{Instrument flow parameters}

In these instrument flow parameters, high voltage $1000 \mathrm{v}$; rejector cutoff frequency $50 \mathrm{hz}$; the 1st, 3rd, 5th, 7th steps: Main pump speed $35 \mathrm{r} / \mathrm{min}$, deputy pump speed $20 \mathrm{r} / \mathrm{min}$, running time $10 \mathrm{~s}$, valve positionR; the 2nd, 4th, 6th, 8th steps: Main pump speed $40 \mathrm{r} / \mathrm{min}$, deputy pump speed $0 \mathrm{r} / \mathrm{min}$, running time 30 s, valve position $\mathrm{L}$.

\section{Results and Discussion}

\section{Kinetic curves of chemiluminescence}

The chemiluminescence of the $\mathrm{Ce}(\mathrm{IV})$ - rhaodamine $\mathrm{B}-\mathrm{H}_{2} \mathrm{SO}_{4}$ system could be strongly inhibited under the selected experimental conditions.

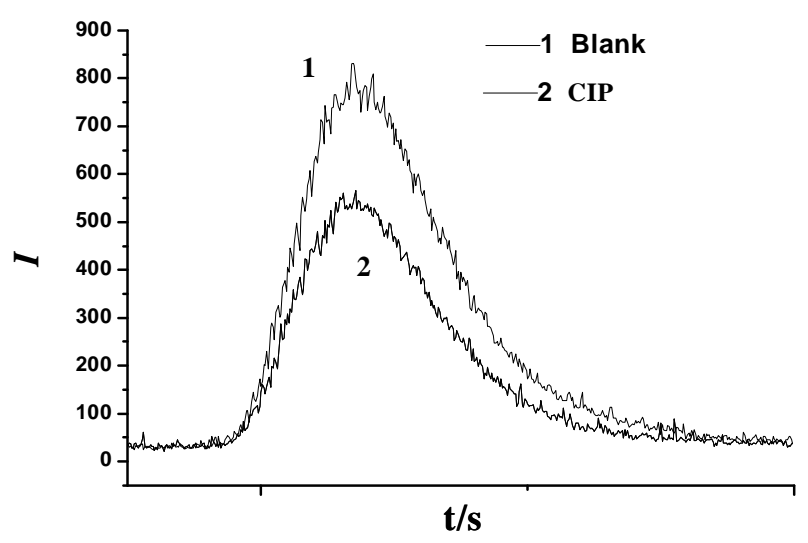

Fig 2 Kinetic curves of chemiluminescence

$$
\mathrm{C}(\mathrm{Cip}): 10.0 \times \mu \mathrm{g} / \mathrm{mL} \text {; }
$$

C(Rhodamine B ):0. $02 \mathrm{mmol} / \mathrm{L} ; \quad \mathrm{C}(\mathrm{Ce}(\mathrm{IV})): 2.0 \mathrm{mmol} / \mathrm{L}$ 


\section{The selection of chemiluminescence experimental conditions}

\section{The influence of $\mathrm{H}_{2} \mathrm{SO}_{4}$ concentration}

The chemiluminescence of the $\mathrm{Ce}(\mathrm{IV})$ - rhaodamine $\mathrm{B}-\mathrm{H}_{2} \mathrm{SO}_{4}$ system could be significant influenced by the concentration of the acid. $\mathrm{H}_{2} \mathrm{SO}_{4}$ was used as the acid medium and the relative Chemiluminescence is $\Delta I$ wasexamined within the scope of 0.02 to $0.12 \mathrm{~mol} / \mathrm{L}$ as shown in figure 3 . After the experiment, the concentration of $\mathrm{H}_{2} \mathrm{SO}_{4}$ in $0.10 \mathrm{~mol} / \mathrm{L}$ was chosen for it made the optimal signal-to-noise ratio.

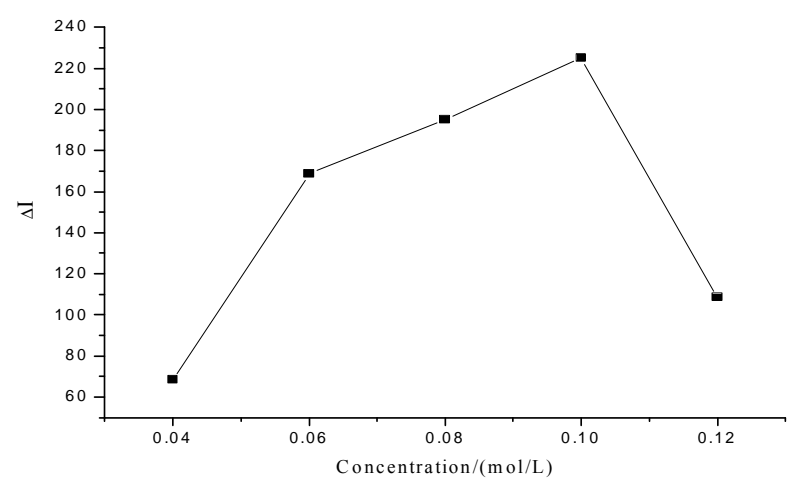

Fig 3 Influence of $\mathrm{H}_{2} \mathrm{SO}_{4}$ concentration on $\mathrm{CL}$ intensity

$\mathrm{C}($ Ciprofloxacin Hydrochloride): $10.0 \mu \mathrm{g} / \mathrm{mL}$;

C(Rhodamine B ):0. $02 \mathrm{mmol} / \mathrm{L} ; \mathrm{C}(\mathrm{Ce}(\mathrm{IV})): 2.0 \mathrm{mmol} / \mathrm{L}$

\section{The influence of $\mathrm{Ce}(\mathrm{IV})$ concentration}

The increase rate of $\Delta I$ was decreased as the concentration of $\mathrm{Ce}$ (IV) rising. In this experiment, the optimal Ce(IV) concentration of $2.0 \mathrm{mmol} / \mathrm{L}$ was chosen as shown in figure 4 .

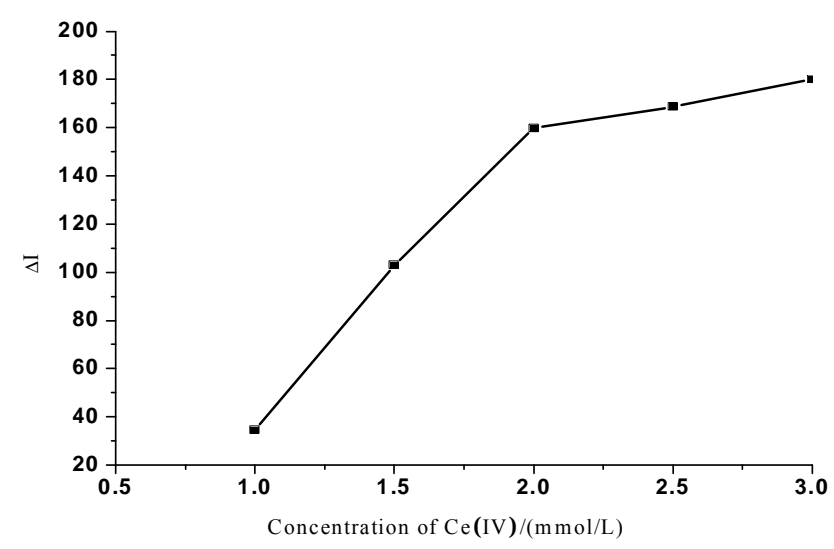

Fig 4 Influence of Ce (IV) concentration on CL intensity

C(Ciprofloxacin Hydrochloride): $10.0 \mu \mathrm{g} / \mathrm{mL} ; \quad$ C(Rhodamine B ):0. $02 \mathrm{mmol} / \mathrm{L}$

\section{The influence of Rhodamine $B$ concentration}

Fixed ciprofloxacin hydrochloride and $\mathrm{Ce}$ (IV) concentration in a constant, the chemiluminescence intensity was detected as the Rhodamine B concentration changing in a range of $0.005 \sim 0.030 \mathrm{mmol} / \mathrm{L}$. As shown in figure 4, the optimal concentration of Rhodamine B is 0.025 $\mathrm{mmol} / \mathrm{L}$. 


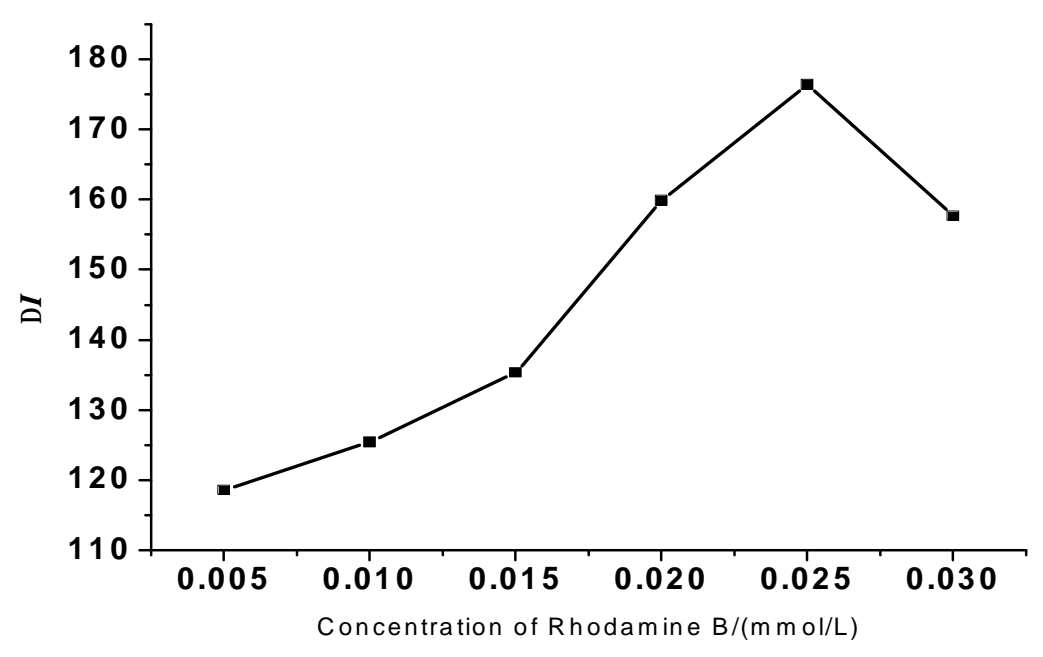

Fig 5 Influence of Rhodamine B concentrate on CL intensity C(Ciprofloxacin Hydrochloride): $10.0 \mu \mathrm{g} / \mathrm{mL} ; \mathrm{C}(\mathrm{Ce}(\mathrm{IV})): 2.0 \mathrm{mmol} / \mathrm{L}$

\section{The influence of interfering substance concentration}

The influence of common metal ions and excipients which in the human body to the luminous intensity was detected. As the experimental results showed, the chemiluminescence would not be interferenced by at least 1000 times of $\mathrm{Cd}^{2+} ; 500$ times of $\mathrm{Cl}^{-} ; 1000$ times of $\mathrm{Na}^{+} ; 150$ times of $\mathrm{Al}^{3+}$ $\mathrm{Zn}^{2+}, \mathrm{C}_{2} \mathrm{O}_{4}{ }^{2} ; 100$ times of glucose, starch, $\mathrm{Ca}^{2+}, \mathrm{Cu}^{2+}, \mathrm{Mg}^{2+} ; 50$ times of citric acid, $\mathrm{Mn}^{2+}, \mathrm{Fe}^{3+}$. But it could be interferenced by 10 times of $\mathrm{Fe}^{2+}$ and $\mathrm{I}^{-}$.

\section{Working curve, Accuracy and Limit of detection}

Under the optimum experimental conditions, luminescence intensity reveals a good linear relationship for the Ciprofloxacin Hydrochloride concentration at the range of $6.0 \times 10^{-7} \sim 8.0 \times 10^{-6}$ $\mathrm{g} / \mathrm{mL}$, and the linear regression equation is: $\Delta I=1.20^{*} 10^{7} \mathrm{C}+34.1$ (the unit is $\mathrm{g} \cdot \mathrm{mL}^{-1} * 10^{-6}$ ), $\mathrm{r}=0.9986$. Based on 11 measurements of blank solution, detection limit $(3 \sigma)$ of $1.0 \times 10^{-9} \mathrm{~g} / \mathrm{mL}$ was obtained. Relative standard deviation (RSD) of $2.0 \%$ was obtained based on 11 measurements for a $5.0 \times 10^{-6}$ $\mathrm{g} / \mathrm{mL}$ CIP solution. The limit of detection (LOD) of $2.0 \times 10-7 \mathrm{~g} / \mathrm{mL}$ was obtained according to the IUPAC.

\section{The sample analysis}

Ten ciprofloxacin capsules were grinded, and the powder was weighed out in the proper amount accurately, and $0.004 \mathrm{~mol} / \mathrm{L} \mathrm{NaOH}$ was added to dissolve it, and then the solution would be filtered and diluted to $50 \mathrm{~mL} .5$ pieces of ciprofloxacin eye drops were dealed in the same way. The sample solution was then diluted to proper volume and determined the amount of ciprofloxacin under the optimized conditions by using the working curve method. The results is showed as table 1

Tab 1 The CIP content and recovery of samples

\begin{tabular}{|c|c|c|c|c|c|c|}
\hline Samples & $\begin{array}{c}\text { Labeled } \\
\text { amount } \\
\text { /mg }\end{array}$ & $\begin{array}{c}\text { Measured } \\
\text { amount } \\
\text { /mg }\end{array}$ & $\begin{array}{c}\text { uv } \\
\text { spectrometry } \\
/ \mathrm{mg}\end{array}$ & & $\begin{array}{l}\text { Added recovery } \\
\qquad / \%\end{array}$ & $\begin{array}{c}\text { Average } \\
\text { recoveries } \\
/ \%\end{array}$ \\
\hline Capsule & 200 & 203.8 & 202.8 & 99.7 & $\begin{array}{lll}103.5 & 99.6 & 104.2\end{array}$ & 101.8 \\
\hline $\begin{array}{c}\text { Eye } \\
\text { drops }\end{array}$ & 15 & 14.9 & 15.1 & 101.2 & $\begin{array}{llll}102.5 & 102.4 & 102.8\end{array}$ & 102.2 \\
\hline
\end{tabular}




\section{Acknowledgements}

This work was financially supported by the key research funding of Hanshan Normal University (2011). Correspondent author is: Professor Ren Nailin.

\section{References}

[1]Haiyun Zhai;Lanchun Zhang;Yufang Pan;etal.Simultaneous Determination of Chloramphenicol, Ciprofloxacin, Nitrofuran Antibiotics and their Metabolites in Fishery Products by CE[J]. Chromatographia.2015,78(7-8):551-556

[2]Xiaoying Xu;Lihong Liu;Zhimin Jia; etal. Determination of enrofloxacin and ciprofloxacin in foods of animal origin by capillary electrophoresis with field amplified sample stacking-sweeping technique[J].Food Chemistry.2015,176:219-225

[3]Scherer,R.;Pereira,Jessica;Firme, Juliete; etal. Determination of Ciprofloxacin in Pharmaceutical Formulations Using HPLC Method with UV Detection[J].Indian Journal of Pharmaceutical Sciences.2014,76(6):541-544

[4] Sevgi Tatar Ulu.Determination of Ciprofloxacin in Human Plasma and Urine by Precolumn Derivatization High Performance Liquid Chromatography with Fluorescence Detection[J].Chinese Journal of Chemistry.2011,29(6):1256-1260

[5] M. N. Patel;B. S. Bhatt;D. S. Gandhi; etal..Spectrophotometric determination of ciprofloxacin by ion pair formation[J].Journal of Analytical Chemistry.2012,67(7):655-660

[6] Zhuoyong Zhang; Xia Li; Xiaoli Wang; etal. Determination of Ciprofloxacin by Flow Injection Analysis Based on Chemiluminescence System[J].Journal of Rare Earths.2006,24(3):285-288 